\title{
SOME CLASSES OF P-ANALYTIC FUNCTIONS DEFINED BY CERTAIN INTEGRAL OPERATOR
}

\author{
KHALIDA INAYAT NOOR
}

Abstract. Let $\mathscr{A}(p), p \in N$, be the class of functions $f(z)=z^{p}+a_{p+1} z^{p+1}+\ldots$, analytic in the open unit disc $E$. For $n=0,1,2, \ldots, n>-p$, a certain integral operator $I_{n+p-1}: \mathscr{A}(p) \longrightarrow$ $\mathscr{A}(p)$ is defined as $I_{n+p-1} f=f_{n+p-1}^{(-1)} \star f$ such that $\left(f_{n+p-1}^{(-1)} \star f_{n+p-1}\right)(z)=\frac{z^{p}}{(1-z)^{p}}$, where $f_{n+p-1}(z)=\frac{z^{p}}{(1-z)^{n+p}}$ and $\star$ denotes convolution or Hadamard product. Using this integral operator, a new subclass $R_{k}(n, p, \alpha)$ of $\mathscr{A}(p), 0 \leqslant \alpha<p$ is introduced in $E$ and some interesting properties of this class are investigated.

Mathematics subject classification (2000): 30C45, 30C50.

Key words and phrases: p-valent functions, convex functions, starlike functions, Hadamard product (or convolution), integral operator, Ruscheweyh derivative.

\section{REFERENCES}

[1] A. W. Goodman, Univalent Functions, Vol I, Washington, N. J., Polygonal Publishing House, 1983.

[2] S. S. MiLler, Differential inequalities and Caratheordary functions, Bull. Amer. Math. Soc., 81, (1975), 79-81.

[3] K. INAYAT NoOR, On new classes of integral operators, J. Nat. Geometry, 16, (1999), 71-80.

[4] K. S. Padmanabhan, R. Parvatham, Properties of a class of functions with bounded boundary rotation, Ann. Polon. Math., 31, (1975), 311-323.

[5] D. A. Patil, N. K. Thakare, On convex hulls and extreme points of $p$-valent starlike and convex classes with applications, Bull. Math. Soc. Sci. Math. R. S. Roumaie (N. S), 27, (1983), 145-160.

[6] B. PINCHUK, Functions with bounded boundary rotation, Isr. J. Math., 10, (1971), 7-16.

[7] S. RuscheweYh, V. Singh, On certain extremal problems for functions with positive real parts, Proc. Amer. Math. Soc., 61, (1976), 329-334. 